\title{
Microstructures Behavior in Biomedical Co-Cr-Mo-C-Si-Mn Alloys Containing Nitrogen
}

\begin{abstract}
Alfirano
Abstract-The precipitates in as-cast and heat-treated biomedical Co-28Cr-6Mo-0.25C-0.175N-(0-1)Si-(0-1)Mn alloys (wt.\%) were investigated. The precipitates observed in the as-cast and heat-treated $\mathrm{Co}-\mathrm{Cr}-\mathrm{Mo}-\mathrm{C}-\mathrm{N}$ alloys were of the M23X6 type, M2X type, $\pi$-phase, and $\eta$-phase. A blocky-dense $\pi$-phase precipitate and a lamellar cellular colony, which consisted of an M2X type precipitate and a $\gamma$-phase, were mainly detected in the as-cast alloys with and without added Si, respectively. The addition of nitrogen caused cellular precipitation, while the addition of Si suppressed it and enhanced the formation of the $\pi$-phase. The addition of nitrogen decreased the time required for complete precipitate dissolution at low heat-treatment temperatures. At high temperatures, complete precipitate dissolution was delayed by the partial melting that accompanied the formation of the precipitates such as the $\pi$-phase.
\end{abstract}

Keywords - Co-Cr-Mo alloy, nitrogen, Si, Mn, solution treatment, cellular precipitation.

\section{INTRODUCTION}

$\mathrm{T}$ he precipitates in biomedical cobalt (Co)-chromium (Cr)-molybdenum (Mo) alloys are known to affect their mechanical and wear properties [1]. Therefore, knowledge of the precipitation of secondary phases in Co-Cr-Mo alloys is essential for establishing appropriate production processes and improving the alloys' properties. The main precipitated phases observed in biomedical Co-Cr-Mo alloys are the intermetallic $\sigma$ phase [2], M23C6-type carbide [3], ๆ-phase (M6CM12C-type carbide) [3], and M7C3-type carbide [4]. In previous studies, the presence of the $\pi$-phase (M2T3X type), a $\beta-\mathrm{Mn}$ structure with $\mathrm{M}$ and $\mathrm{T}$ : metallic elements and $\mathrm{X}$ : carbon and nitrogen [5] and $\chi$-phase (intermetallic compound, with an $\alpha-\mathrm{Mn}$ structure) [6] in the Co-Cr-Mo alloy was found.

In recent years, nitrogen has been attracting attention as an effective alloying element for improving the mechanical properties and workability of Co-Cr-Mo alloys [7]. Several authors have studied the microstructures formed in Co-Cr-Mo alloys with nitrogen content [8]. However, the phase formation/dissolution of the secondary phases was not fully understood in those Co-Cr-Mo-C-N alloys. In this study, the precipitate behavior in as-cast and heat-treated Co-28Cr-6Mo-0.25C-0.175N-(0-1)Si-(0-1)Mn alloys (wt.\%) was investigated, with a focus on phases and dissolution of the precipitates.

\section{METHOD}

Table 1 gives the chemical composition of the alloys used in this study. Alloy ingots (diameter: $34 \mathrm{~mm}$, height: $100 \mathrm{~mm}$ ) were prepared using an induction melting furnace under a nitrogen-containing atmosphere and cast in a copper mold. These ingots were cut into disks with a diameter of $34 \mathrm{~mm}$ and a thickness of $5 \mathrm{~mm}$, which were then cut into four equal parts. Heat treatment was performed in an electric resistance tube furnace at 1448-1548 $\mathrm{K}$ for $0-3.2 \mathrm{ks}$ in Ar atmosphere, and was

\footnotetext{
${ }^{1}$ Alfirano is with Departement of Metallurgy Engineering, Faculty of Engineering, University of Sultan Ageng Tirtayasa, Cilegon, Indonesia. E-mail: alfirano@ft-untirta.ac.id.
}

water-quenched immediately after the completion of the heat treatment.

The specimens were cut along the thickness direction, and the cross section was mechanically ground with emery paper (maximum grit size: 1500) and polished with $1-\mu \mathrm{m}$ diamond paste. The specimens were electrolytically etched in 10\% $\mathrm{H} 2 \mathrm{SO} 4-$ methanol solution at $6 \mathrm{~V}$ for microstructure observations. The microstructures of the as-cast and heat-treated alloys were observed using an optical microscope (OM, Olympus, Tokyo, Japan, BX60M) and a scanning electron microscope (SEM, Philips, Hillsboro, OR, XL30FEG). The precipitates in the heat-treated alloys were observed using thin foil transmission electron microscopy (TEM, JEOL, Tokyo, Japan, JEM-2100). The precipitates formed in the as-cast and heat-treated alloys were electrolytically extracted at room temperature in $10 \% \mathrm{H} 2 \mathrm{SO} 4$ aqueous solution at $2 \mathrm{~V}$. The phases of the extracted precipitates were identified using X-ray diffraction (XRD, Bruker AXS, Karlsruhe, Germany, D8Advance). The XRD patterns were obtained using $\mathrm{Cu} \mathrm{K} \alpha$ radiation.

\section{RESULT AND DISCUSSION}

\section{A. Precipitates in As-Cast Alloys}

Figures 1 (a)-(c) show the microstructures of the ascast alloys. In the alloys containing $\mathrm{Si}$, i.e., 10-N, blocky-dense precipitates were observed in the interdendritic region. In contrast, in the alloys without added $\mathrm{Si}$, i.e., 01-N, lamellar cellular precipitation was observed and was primarily located on the grain boundaries. The XRD patterns of the precipitates that were electrolytically extracted from the as-cast alloys are shown in Figure 2, along with JCPDS card nos. 035$0803(\mathrm{Cr} 2 \mathrm{~N})$. The $\mathrm{Cr} 2 \mathrm{~N}$ type phase is referred to as $\mathrm{M} 2 \mathrm{X}$ because $\mathrm{Cr}$ and nitrogen were partially substituted with other elements. $\pi$-phase and $\mathrm{M}_{2} \mathrm{X}$ type were the main precipitates in the as-cast alloys with and without added $\mathrm{Si}$, respectively. TEM analysis showed that the cellular colony in the as-cast $00-\mathrm{N}$ and $01-\mathrm{N}$ alloys consisted of plate-like $\mathrm{M}_{2} \mathrm{X}$ type precipitates and the $\gamma$-phase. These results indicate that the white precipitates in the cellular colony in Figures 1 (a) and (c) are $\mathrm{M}_{2} \mathrm{X}$ type.

Since the $\mathrm{M}_{2} \mathrm{X}$ type precipitate was not formed in the Co-Cr-Mo-C and Co-Cr-Mo-C-Si-Mn [5] alloys, 
nitrogen appears to be the cause of the formation of the lamellar cellular colony with $\mathrm{M}_{2} \mathrm{X}$ type precipitates. A lamellar cellular colony with $\mathrm{M}_{2} \mathrm{X}$ type precipitates has been reported in aged [9] and as-cast [10] stainless steels with high nitrogen and low carbon contents.

In Co-Cr-Mo alloys, Rosenthal et al. [11] reported the formation of coarse lamellar cellular colonies in an ascast $\mathrm{Co}-28 \mathrm{Cr}-6 \mathrm{Mo}-0.25 \mathrm{C}$ alloy; the cellular colonies comprised an $\mathrm{M}_{23} \mathrm{C}_{6}$ type precipitate and a $\gamma$-phase. The appearance of those cellular colonies was very similar to that observed in this study. They stated that discontinuous and eutectoid reactions are possible mechanisms for the formation of the cellular colonies [12]; a discontinuous reaction mechanism was specifically proposed for the formation of the coarse cellular colonies.

In this study, since the cellular colonies consisted of $M_{2} X$ type precipitates and the $\gamma$-phase, the $\gamma_{1} \rightarrow \gamma_{2}+M_{2} X$ discontinuous reaction is a potential mechanism for the formation of cellular precipitation during cooling in casting. The $\gamma_{1}$ and $\gamma_{2}$-phases describe the fcc Co-based metallic phase with different chemical compositions. Precipitation of the cellular colonies on the grain boundary supports the discontinuous reaction mechanism. In this work, lamellar cellular precipitation of $\mathrm{M}_{2} \mathrm{X}$ type precipitates was not observed in the alloys with added $\mathrm{Si}$. This result suggests that $\mathrm{Si}$ suppressed the formation of the $\mathrm{M}_{2} \mathrm{X}$ type precipitate. $\mathrm{Si}$ is known to increase the thermodynamic activity of carbon in steels [13]. The increase in carbon activity due to the addition of Si causes the formation of carbon-rich carbon-nitrides such as the $\pi$-phase. Escobede et al. [14] reported the formation of carbide precipitates in as-cast biomedical Co-Cr-Mo alloys with added nitrogen. The alloy that Escobede et al. used contained carbon in 0.41 to 0.45 wt. $\%$ and nitrogen in 0.035 to 0.15 wt. $\%$. The carbon contents higher than that of ASTM F 75 may stabilize carbides and cause the formation of $\eta$-phase and $\mathrm{M}_{23} \mathrm{C}_{6}$ type precipitates. This could be due to the fact that its nitrogen content was slightly less than that in the $00-\mathrm{N}$ alloy, which could lead to the formation of $\mathrm{M}_{23} \mathrm{C}_{6}$ type precipitates. These results suggest that the formation of $\mathrm{M}_{2} \mathrm{X}$ type precipitates is suppressed by the addition of $\mathrm{Si}$ and/or carbon that stabilize $\pi$-phase and $\mathrm{M}_{23} \mathrm{C}_{6}$ (and/or $\eta$-phase) type precipitates, respectively, though nitrogen is an essential element for the formation of $\mathrm{M}_{2} \mathrm{X}$ type precipitates.

\section{B. Vibration}

The phase of the precipitates in the incomplete dissolution region and the complete precipitate dissolution region are summarized in Figure 3. In this figure, the phases are listed from left to right in order of decreasing content, which was evaluated using XRD. At high temperatures such as $1548 \mathrm{~K}$, the $\pi$-phase was the major precipitate. Meanwhile, at temperatures below $1523 \mathrm{~K}, \eta$-phase and $\theta$-phase precipitates were primarily observed in the alloys with and without added $\mathrm{Si}$, respectively.

Complete precipitate dissolution was achieved in all of the alloys and the temperature conditions. The complete precipitate dissolution depended on the alloy composition. In the cases of the $10-\mathrm{N}$ and $01-\mathrm{N}$ alloys, the holding time required for complete precipitate dissolution at $1548 \mathrm{~K}$ was longer than that at $1523 \mathrm{~K}$, and the boundary between the complete and incomplete precipitate dissolution regions can be described as $\mathrm{C}$ curved with a nose at $\sim 1523 \mathrm{~K}$. The $\mathrm{C}$-curved shape of the boundary between the complete and incomplete precipitate dissolution regions was reported to be caused by partial melting of the interdendritic parts in the alloys that accompanied $\pi$-phase formation [5]. This mechanism can be applied to $10-\mathrm{N}$ and $01-\mathrm{N}$ alloys, in which $\pi$-phase formation was observed under the as-cast condition and after heat treatment at 1523 and $1548 \mathrm{~K}$ for short holding periods. The enhancement of precipitate formation at higher temperatures such as $1548 \mathrm{~K}$ after the addition of nitrogen could be the reason for the increase in the holding time required for complete precipitate dissolution. In contrast, at lower temperatures the addition of nitrogen decreased the holding time required for complete precipitate dissolution.

In addition, the diffusion coefficients of nitrogen and carbon in Co were reported as $3.3 \times 10^{-10} \mathrm{~m}^{2} / \mathrm{s}$ and $1.1 \times 10^{-}$ ${ }^{10} \mathrm{~m}^{2} / \mathrm{s}$, respectively, in $\mathrm{Co}$ at $1473 \mathrm{~K}$ [15]. The precipitate dispersion and the higher diffusion coefficient of nitrogen as compared to that of carbon appear to cause the increased apparent precipitate dissolution rates and decreased required holding time for complete precipitate dissolution in the alloy with added nitrogen at low temperatures. In the $01-\mathrm{N}$ alloy, the area of complete precipitate dissolution was wider than that of the alloys with added Si. Because the addition of Mn was reported to decrease the carbon activity in Fe-based alloys [21], which is opposite to the effect observed upon adding $\mathrm{Si}$, the Mn supplementation could increase the apparent dissolution rate of precipitates, resulting in a shortened holding time for complete precipitate dissolution [9]

\section{CONCLUSION}

The microstructures of biomedical Co-Cr-Mo-C-N-Si$\mathrm{Mn}$ alloys were investigated before and after heat treatment with a focus on the effect of nitrogen on the phases and dissolution of the precipitates. The following results were obtained:

1. A blocky-dense $\pi$-phase precipitate and lamellar cellular colony, which consisted of an $\mathrm{M}_{2} \mathrm{X}$ type precipitate and a $\gamma$-phase, were mainly detected in the as-cast alloys with and without added $\mathrm{Si}$, respectively. Nitrogen caused the formation of the $\mathrm{M}_{2} \mathrm{X}$ type precipitate, but $\mathrm{Si}$ appeared to suppress cellular precipitation resulting in the formation of the $\pi$-phase precipitate.

2. The phases of the precipitates observed in the heattreated alloys were $\mathrm{M}_{23} \mathrm{X}_{6}$ type, $\mathrm{M}_{2} \mathrm{X}$ type, $\eta$-phase, and $\pi$-phase. The addition of nitrogen strongly enhanced the formation of the $\mathrm{M}_{2} \mathrm{X}$ type and the $\eta$ phase precipitates at high and low heat treatment temperatures, respectively.

3. Nitrogen appears to decrease the holding time required for complete precipitate dissolution at low heat treatment temperatures. It also delays complete precipitate dissolution at $1548 \mathrm{~K}$ due to the enhancement of $\pi$-phase formation. 


\section{REFERENCES}

[1]. A. Chiba, N. Nomura, and Y. Ono, "Microstructure and mechanical properties of biomedical $\mathrm{Co}-29 \mathrm{Cr}-8 \mathrm{Mo}$ alloy wire fabricated by a modified melt-spinning process,": Acta Mater., vol. 55, pp. 2119-2128, 2007.

[2]. M. Caudillo, M. Herrera-Trejo, M. R. Castro, E. Ramírez, C. R. González, and J. I. Juárez, "On carbide dissolution in an as-cast ASTM F-75 alloy,” J. Biomed. Mater. Res., vol. 59, pp. 378-385, 2002.

[3]. M. Herrera, A. Espinoza, J. Méndez, M. Castro, J. López, and J. Rendón, "Effect of $\mathrm{C}$ content on the mechanical properties of solution treated as-cast ASTM F-75 alloys," J. Mater. Sci.: Mater. Med., vol. 16, pp. 607-11, 2005.

[4]. T. Kilner, R.M. Pilliar, G.C. Weatherly, and C. Allibert, "Phase identification and incipient melting in a cast $\mathrm{Co}-\mathrm{Cr}$ surgical implant alloy,” J. Biomed. Mater. Res., vol. 16, pp. 63-79, 1982.

[5]. Alfirano, S. Mineta, S. Namba, T. Yoneda, K. Ueda, and T. Narushima, "Precipitates in as-cast and heat-treated ASTM F75 Co-Cr-Mo-C alloys containing Si and/or Mn," Metall. Mater. Trans. A, vol. 42A, pp. 1941-1949, 2011.

[6]. T. Narushima, Alfirano, S. Mineta, S. Namba, T. Yoneda, and K. Ueda "Precipitates in biomedical Co-Cr-Mo-C-Si-Mn alloys." Adv. Mater. Res., vol. 277, pp. 51-58, 2011.

[7]. B.S. Lee, H. Matsumoto, and A. Chiba, "Fractures in tensile deformation of biomedical Co-Cr-Mo-N alloys," Mater. Lett., vol. 65 , pp. 843-846, 2011.
[8]. Y. Yamashita, Y. Li, H. Matsumoto, Y. Koizumi, and A. Chiba, "Construction of processing map for biomedical Co-29Cr-6Mo$0.23 \mathrm{C}-0.14 \mathrm{~N}$ alloy by using compression tests," Mater. Trans., vol. 4, pp. 780-786, 2011.

[9]. T. Kilner, A.J. Dempsey, R.M. Polliar, and G.C. Weatherly, "The effects of nitrogen additions to a cobalt-chromium surgical implant alloy,” J. Mater. Sci., vol. 22, pp. 565-574, 1987.

[10]. R.D. Knutsen, C.I. Lang, and J.A. Basson, "Grain refinement of biomedical Co-27Cr-5Mo-0.16N alloy by reverse transformation," Acta Mater., vol. 52, pp. 2407-2417, 2004.

[11]. R. Rosenthal, B.R. Cardoso, I.S. Bott, R.P.R. Paranhos, and E.A Carvalho, "Phase characterization in as-cast F-75 $\mathrm{Co}-\mathrm{Cr}-\mathrm{Mo}-\mathrm{C}$ alloy," J. Mater. Sci., vol. 45, pp. 4021-4028, 2010.

[12]. M. Kikuchi, M. Kajihara, and S.-K. Choi: Mat. Sci. Eng. A, vol. 146, pp. 131-150, 1991.

[13]. B.C. De Cooman, "Structure-properties relationship in TRIP steels containing carbide-free bainite," Curr. Opin. Solid State Mater. Sci., vol. 8, pp. 285-303, 2004.

[14]. J. Escobedo, J. Méndez, D. Cortéz, J. Gomé, M. Méndez, and H Mancha, "Effect of nitrogen on the microstructure and mechanical properties of a Co-Cr-Mo alloy," Mater. Des., vol. 17, pp. 79-83, 1996.

[15]. A.T. Allen and D.L. Douglass, "Internal-Nitriding Behavior of $\mathrm{Ni}-\mathrm{V}$ and Ni-3Nb Alloys", Oxid. Met., vol. 51, pp. 1-22, 1999
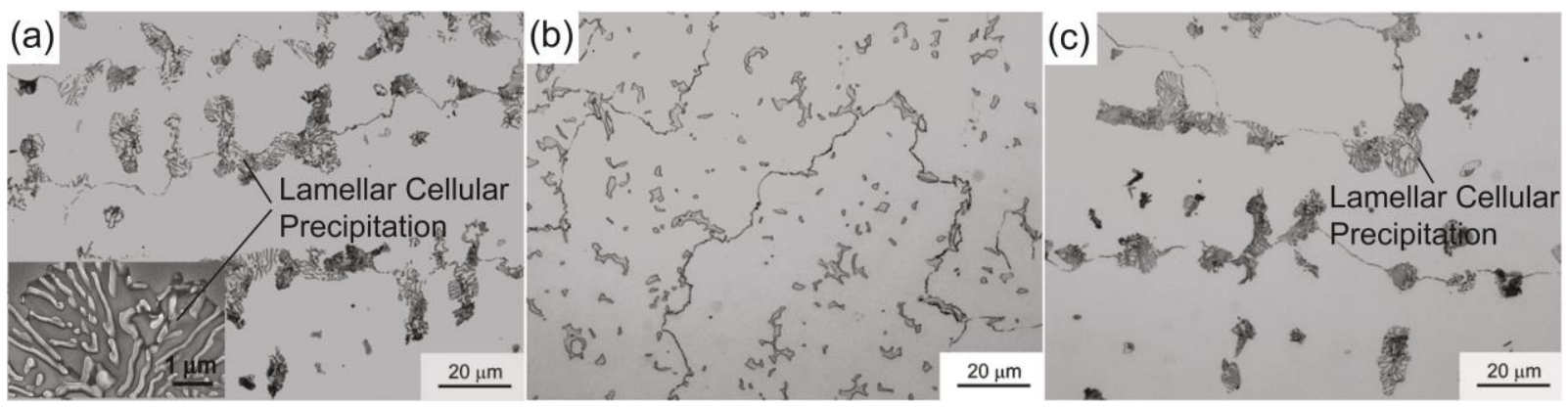

Figure. 1. Microstructure of as-cast (a) 00-N, (b) 10-N, and (c) 01-N alloys

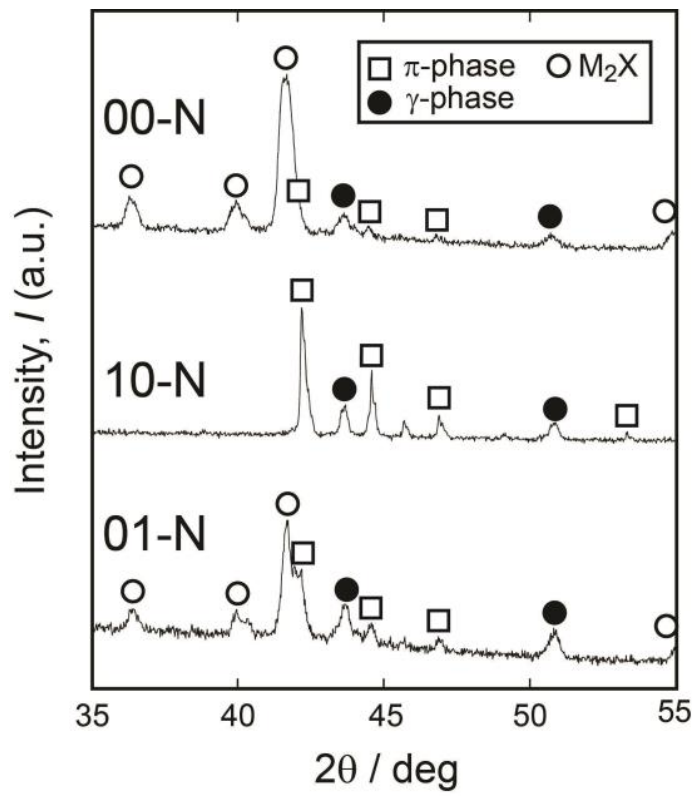

Figure. 2. XRD patterns of precipitates electrolytically extracted from as-cast alloys 


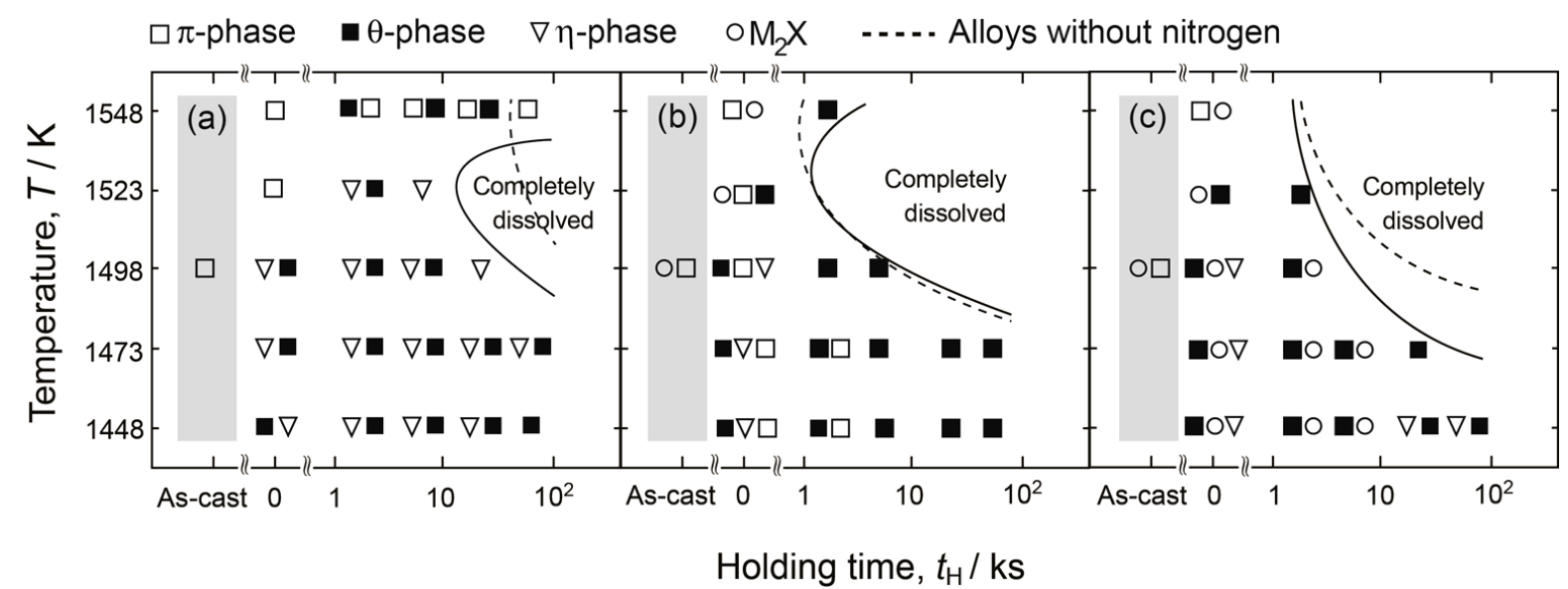

Figure. 3. Phase of precipitate under as-cast and incomplete dissolution conditions and complete precipitate dissolution region of (a) $00-\mathrm{N}$, (b) $10-\mathrm{N}$, and (c) $01-\mathrm{N}$ alloys

TABLE 1.

CHEMICAL COMPOSITION OF ALLOYS USED IN THIS STUDY (WT\%)

\begin{tabular}{ccccccccccc}
\hline \hline Abbreviation & $\mathrm{Cr}$ & $\mathrm{Mo}$ & $\mathrm{C}$ & $\mathrm{N}$ & $\mathrm{Si}$ & $\mathrm{Mn}$ & $\mathrm{P}$ & $\mathrm{S}$ \\
\hline $00-\mathrm{N}$ & 27.65 & 6.22 & 0.25 & 0.19 & $<0.001$ & 0.001 & $<0.001$ & $<0.001$ & $\mathrm{Co}$ \\
$10-\mathrm{N}$ & 27.9 & 6.17 & 0.25 & 0.15 & 1.21 & 0.001 & 0.002 & $<0.001$ & Bal. \\
$01-\mathrm{N}$ & 27.77 & 6.09 & 0.24 & 0.19 & $<0.001$ & 1.15 & 0.002 & $<0.001$ & Bal. \\
\hline \hline
\end{tabular}

